\title{
Candidaemia and antifungal therapy in a French University Hospital: rough trends over a decade and possible links Boualem Sendid $^{* 1,2}$, Angélique Cotteau ${ }^{3}$, Nadine François ${ }^{1}$, Annie D'Haveloose ${ }^{3}$, Annie Standaert ${ }^{1}$, Daniel Camus ${ }^{2}$ and Daniel Poulain ${ }^{1,2}$
}

Address: ${ }^{1}$ Inserm, U799, Lille, F-59045 France;Laboratoire de Mycologie Fondamentale et Appliquée, Faculté de Médecine, Lille, F-59045, France, ${ }^{2}$ Laboratoire de Parasitologie-Mycologie, CHRU, Lille, F-59045, France and ${ }^{3}$ Département de Pharmacie, CHRU, Lille, F-59045 Lille, France

Email: Boualem Sendid* - bsendid@univ-lille2.fr; Angélique Cotteau - a-leroy@chru-lille.fr; Nadine François - N-FRANCOIS@CHRU-LILLE.FR; Annie D'Haveloose - a-dhaveloose@chru-lille.fr; Annie Standaert - astandaert@univ-lille2.fr; Daniel Camus - d-camus@chru-lille.fr; Daniel Poulain - dpoulain@univ-lille2.fr

* Corresponding author

Published: 02 May 2006

BMC Infectious Diseases 2006, 6:80 doi:10.1 186/147/-2334-6-80
Received: 17 October 2005

Accepted: 02 May 2006

This article is available from: http://www.biomedcentral.com/I47I-2334/6/80

(C) 2006 Sendid et al; licensee BioMed Central Ltd.

This is an Open Access article distributed under the terms of the Creative Commons Attribution License (http://creativecommons.org/licenses/by/2.0), which permits unrestricted use, distribution, and reproduction in any medium, provided the original work is properly cited.

\begin{abstract}
Background: Evidence for an increased prevalence of candidaemia and for high associated mortality in the 1990s led to a number of different recommendations concerning the management of at risk patients as well as an increase in the availability and prescription of new antifungal agents. The aim of this study was to parallel in our hospital candidemia incidence with the nature of prescribed antifungal drugs between 1993 and 2003.
\end{abstract}

Methods: During this 10-year period we reviewed all cases of candidemia, and collected all the data about annual consumption of prescribed antifungal drugs

Results: Our centralised clinical mycology laboratory isolates and identifies all yeasts grown from blood cultures obtained from a 3300 bed teaching hospital. Between 1993 and 2003, 430 blood yeast isolates were identified. Examination of the trends in isolation revealed a clear decrease in number of yeast isolates recovered between 1995-2000, whereas the number of positive blood cultures in 2003 rose to 1993 levels. The relative prevalence of Candida albicans and C. glabrata was similar in 1993 and 2003 in contrast to the period 1995-2000 where an increased prevalence of $C$. glabrata was observed. When these quantitative and qualitative data were compared to the amount and type of antifungal agents prescribed during the same period (annual mean defined daily dose: 266274I; annual mean cost: $615629 €$ ) a single correlation was found between the decrease in number of yeast isolates, the increased prevalence of $C$. glabrata and the high level of prescription of fluconazole at prophylactic doses between 1995-2000.

Conclusion: Between 1993 and 2000, the number of cases of candidemia halved, with an increase of $C$. glabrata prevalence. These findings were probably linked to the use of Fluconazole prophylaxis. Although it is not possible to make any recommendations from this data the information is nevertheless interesting and may have considerable implications with the introduction of new antifungal drugs. 


\section{Background}

Bloodstream infections are a major cause of morbidity and mortality in developed countries. Recent statistics in the USA show that these infections are the tenth leading cause of death overall [1]. Their true incidence remains unknown, but it is estimated that around 250000 cases occur annually in the USA alone [2]. In France, the prevalence of septicaemia in the hospital environment has been estimated to be around $0.4 \%$ [3]. Infections due to Candida species are an increasingly important complication in hospitalised patients [4-6]. North American and European surveillance studies have provided recommendations about the definition of risk factors and epidemiology of candidaemia [7,8]. Large scale epidemiological studies conducted in Europe [9] and the USA [10] show that Candida species are now the fourth most common cause of hospital-acquired bloodstream infection [11]. Candida albicans is the most common cause of candidaemia, and in general has remained susceptible in vitro to both polygenic drugs and fluconazole (FCZ) [12,13]. As the use of FCZ has increased, however, it has become more important to screen for azole resistance among bloodstream isolates or an increase in frequency of bloodstream infection due to species other than C. albicans, which have a higher incidence of in vitro azole resistance (e.g., C. glabrata and C. krusei) [14,15]. In this study, a longitudinal surveillance of bloodstream infections caused by Candida species was carried out in a 3300 bed teaching hospital during the 10-year period 1993-2003. The results were correlated with the use of FCZ over the same period.

\section{Methods}

\section{Mycological investigations}

A retrospective study of positive blood cultures for Candida species between 1993-2003 was carried out by the mycology service. This study allowed us to determine the number of cases of candidaemia annually; candidaemia was defined as one or more positive blood cultures for Candida species isolated from patients with clinical signs of infection. During this period three blood culture systems were used: Bio Argos (Sanofi Diagnostics Pasteur, Marnes-la-Coquette, France) and BactAlert 3D (Organon Teknika, France) were used successively by the bacteriology laboratory for the isolation of microorganisms in cases of septicaemia. When yeasts were isolated, the strain was transferred to the mycology laboratory for identification. In parallel, the Bactec 9050 system with aerobic mycosis IC/F medium (Becton Dickinson, USA) has been used by the mycology laboratory since November 1999. Mycosis IC/F medium, which is specifically adapted for the growth of fungi, significantly reduces the mean time for yeast detection(in particular C. albicans and C. glabrata) [16].
For all blood culture systems, the blood culture flasks were mixed with $10 \mathrm{ml}$ of blood and then incubated at $37^{\circ} \mathrm{C}$ for 7 days. A control for microbial growth was carried out automatically.

\section{Identification of strains}

Positive samples were examined directly after staining with Giemsa or toluidine blue and subculture on Sabouraud's agar containing gentamycin $(40 \mathrm{mg} / \mathrm{L})$. All strains isolated were identified using the germ tube test, chlamydospore production and API 32C system (Bio-Mérieux, Marcy l'Etoile, France). Since 1997, all strains have also been subcultured on chromogenic medium CHROMagar, which allows the presumptive identification of some Candida species. The germ tube test has been replaced with Bichrolatex albicans, a rapid immunological test for the identification of C. albicans.

\section{Pharmaco-economic investigations}

The annual consumption of antifungal drugs during the same period was determined from pharmacy data (TAGE, GEF, and Mc Kesson softwares). The annual consumption of a drug takes into account all hospital services using the drug, with any eventual returns of the product deducted. This consumption is expressed as total milligrams of active drug used. The antifungal drugs included in the evaluation were indicated for either prophylaxis or curative treatment of candidaemia: 5-fluorocytosine (5FC; Ancotil $\left.^{\circledast}\right)$, amphotericin B (AMB; Fungizone $\left.{ }^{\circledR}\right)$, amphotericin B lipid complex (ABLC; Abelcet $^{\circledR}$ ), liposomal amphotericin B (AMBD; AmBisome $\left.{ }^{\circledast}\right)$, caspofungin (CAS; Cancidas $^{\circledast}$ ), voriconazole (VCZ; Vfend ${ }^{\circledast}$ ) and fluconazole (FCZ; Triflucan ${ }^{\circledR}$ ). The data collected included antifungal use and the number of cases of candidaemia observed during the same period.

\section{Results}

\section{Distribution of candidaemia cases over the study period}

During the period 1993-2003, an average of 45762 blood cultures were analysed annually by the bacteriology laboratory and an average of 659 by the mycology laboratory. Among these, 430 (1/1000; 0.1\%) were positive for Candida species compared with $11 \%$ for bacteria. The cases of candidaemia originated most frequently from the intensive care service $(36 \%)$, surgical unit $(20 \%)$, cancer unit $(13 \%)$, gastroenterolgy (6\%), haematology (6\%) and paediatric service (5\%). The other services (burns, geriatrics, pneumology, nephrology, internal medicine, etc.) represented only $14 \%$ of isolates overall. The annual incidence of positive blood cultures is shown in Figure 1. Between 1995 and 2001, a decrease in number of cases of candidaemia was observed. In general, C. albicans was the predominant species making up $61.5 \%$ of isolates. Conversely, a significant variation was observed for nonalbicans species, with $C$. glabrata predominating between 


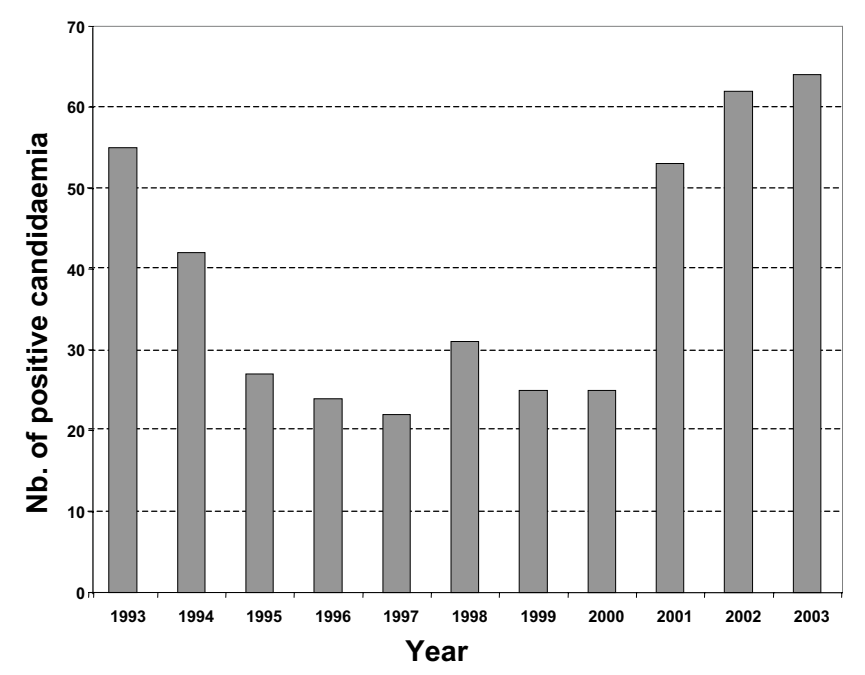

Figure I

Number of episodes of candidaemia recorded during 19932003 in a 3300 bed French university hospital.

1995 and 2001, with a peak incidence of 27\% in 1997 (Figure 2). Outside this period, C. parapsilosis and C. tropicalis were the most frequent species isolated after C. albicans. C. parapsilosis was the predominant non-albicans species before 1995 (with a mean incidence of 14.7\%), and after 2001. The mean incidence of C. tropicalis was $9 \%$, with a peak of $13 \%$ in 1998 . Little variation was observed for $C$. krusei which remained below $4 \%$. The other species included C. lusitaniae $(\mathrm{n}=3)$, C. kefyr $(\mathrm{n}=$ $2), C$. guilliermondii $(n=2)$ and $C$. norvegensis $(n=1)$. The evolution and proportion of different Candida species in relation to the main hospital services caring for patients at risk of systemic candidosis is shown in Figure 3. C. albicans represented more than $60 \%$ of isolates recovered from the different services except for oncology/haematology where C. albicans represented only $32 \%$ of isolates. This reduction in isolation of $C$. albicans was associated with an increase in isolation of C. tropicalis (24\%), C. glabrata (16\%) and C. krusei (12\%). No isolates of C. glabrata were recovered from the paediatric service. Although the number of strains isolated was small $(\mathrm{n}=12)$, no case of candidaemia caused by $C$. krusei was observed in paediatrics or gastroenterology.

\section{Variation in consumption of antifungal drugs}

Antifungal use in milligrams between 1993-2003 was converted to the defined daily dose (DDD) to enable interpretation. The DDD for the different drugs was: 70 $\mathrm{mg}$ for $\mathrm{AMB}, 210 \mathrm{mg}$ for AMBD, $350 \mathrm{mg}$ for ABLC, $400 \mathrm{mg}$ for FCZ, $10000 \mathrm{mg}$ for 5FC, $50 \mathrm{mg}$ for CAS and $400 \mathrm{mg}$ for VCZ.
Figure 4 shows that different formulations of $\mathrm{AMB}$ were used constantly (mean DDD 5102), with a progressive decrease in AMB use after 1999 in favour of lipid formulations (ABLC and AMBD). ABLC has been used since 1997 with a constant mean annual consumption of 647 DDD. AMBD has been used since 1998 with a considerable increase in use documented since 1999. Low consumption of 5FC was noted over the whole study period (mean DDD: 425). Use of this drug, often as combined therapy, was significant until 1995.

Evaluation of FCZ use revealed a net increase since 1997. The mean DDD for the period 1993-1996 was 8412 compared with a mean DDD of 13184 between 1997-2002. The recent introduction of VCZ (2002) and CAS (2001) has increased the number of drugs available to treat candidaemia. The large increase in use of VCZ seems to correlate with a reduction in FCZ use in 2003 (Figure 4). CAS consumption is currently equivalent to that of AMBD.

\section{Variation in consumption of fluconazole related to candidaemia}

If FCZ consumption and profile of Candida species isolated from blood cultures are superimposed it can be seen that the increase in FCZ use correlates closely with a change in profile of non-albicans species isolated with $C$. glabrata predominating (Figure 5).

Analysis of FCZ consumption during the study period reveals that two types of prescription were possible: lowdose (dose between 50-100 mg) and high-dose therapy (dose $>200 \mathrm{mg}$ ) (Figure 6 ). A reduction in prescription of lower doses was observed after 1997, coinciding with a $40 \%$ reduction in number of cases of candidaemia compared to 1993 and the emergence of C. glabrata as a significant cause of infection (27\%) (Figure 6). An inversion in prescription of low- versus high-dose FCZ was observed after 2000. During the period 1998-2000, the ratio of the two doses was nearly 1 . The relative peak in percentage of low-dose FCZ used in 2003 corresponded to a progressive reduction in high-dose FCZ in favour of VCZ.

\section{Discussion}

The incidence of nosocomial fungal infections has continued to rise over the past two decades in parallel with advances in medical and surgical procedures. Bone marrow and solid organ transplant procedures, surgery and medical intensive care have largely increased the number of profoundly immunosuppressed patients at high risk of opportunistic infection $[8,11]$. Invasive fungal infections are usually severe in these patients and are difficult to diagnose and treat [17]. A significant proportion of these patients do not die from their underlying pathology but die of infectious complications often related to a deep fungal infection. Candida species are among the most fre- 


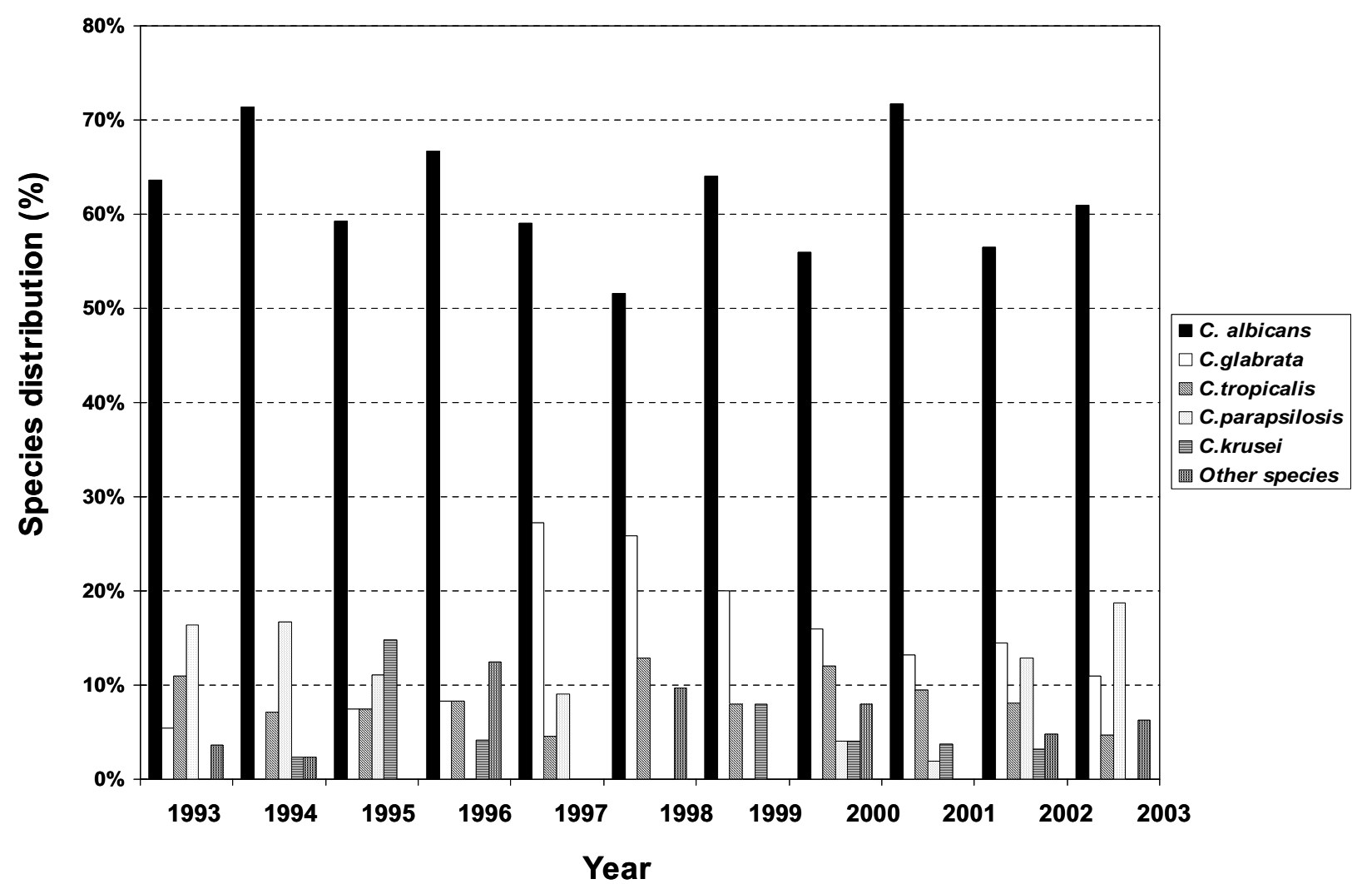

Figure 2

Distribution of Candida species as bloodstream isolates by year (1993-2003).

quently isolated agents of invasive fungal infection [18], and account for $8-10 \%$ of hospital-acquired cases of septicaemia [15]. In spite of recent progress in antifungal chemotherapy, the mortality rate from these infections continues to rise [19]. Their economic impact has also been recognised, linked largely to the empirical use of systemic antifungal drugs and a prolongation of hospital stay (on average 30 days), which is necessary for optimal treatment and control of candidaemia $[20,21]$. This overspend is estimated at $40.000 \$$ per patient in some American intensive care units [21].

Although the procedure suffers from a lack of sensitivity, blood culture remains an important tool in the diagnosis of invasive candidosis [22]. According to recommendations from some experts and learned societies, a single positive blood culture is sufficient to make a diagnosis of invasive candidosis and justifies the initiation of antifungal treatment [23]. In these conditions, epidemiological studies on the number and type of Candida species isolated from blood cultures are an important prerequisite to developing effective antifungal strategies.

The current report presents the results of a retrospective study of cases of candidaemia during the last decade (1993-2003), in a French university hospital. The study did not include patients with HIV, who were cared for in an infectious diseases service not attached to our hospital.

Analysis of the data obtained demonstrated that the number of cases of candidaemia halved between 1993 and 2000. This trend was probably linked to the use of FCZ prophylaxis. The results also demonstrated that $C$. albicans was the most frequently isolated species, compris- 


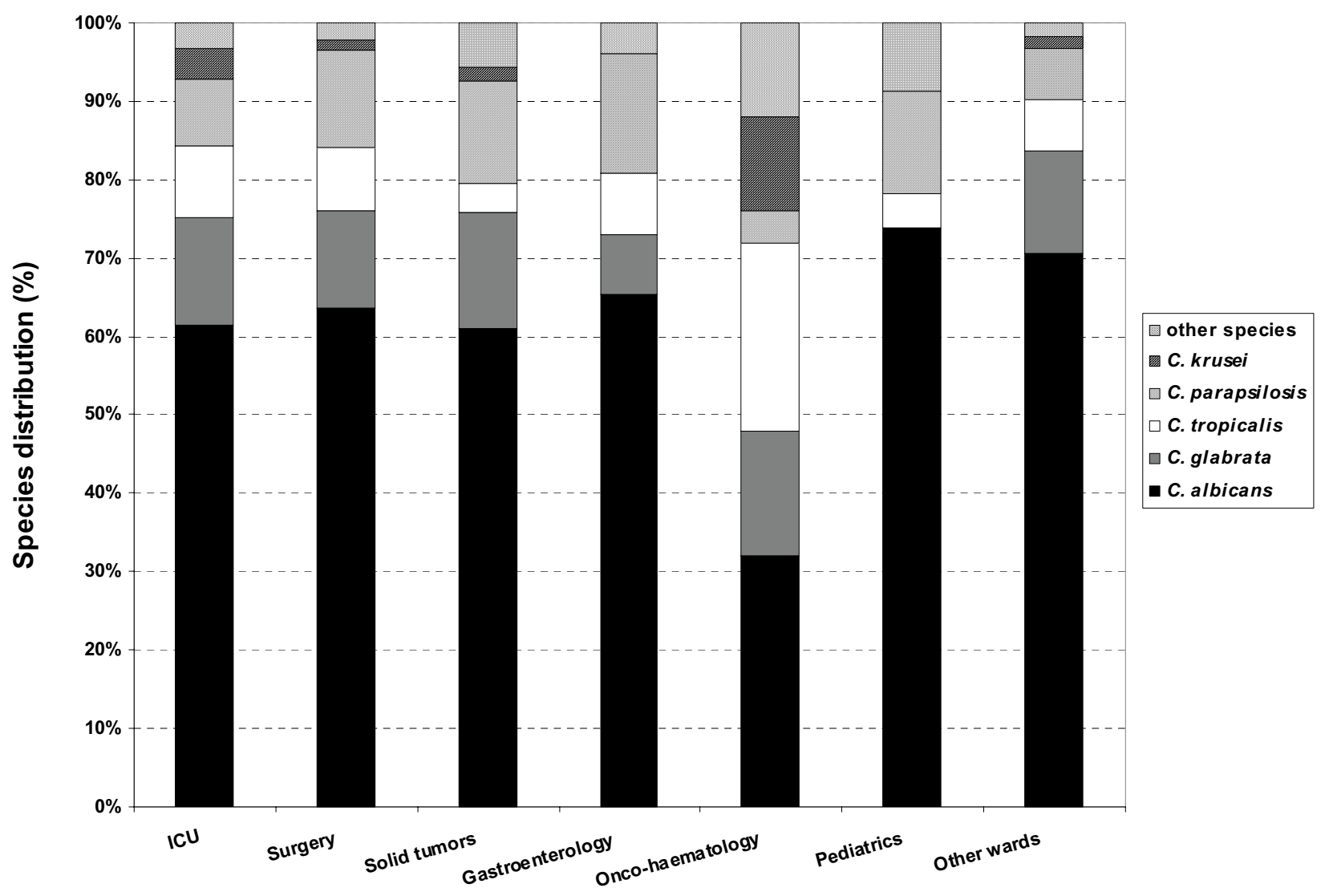

Figure 3

Distribution (percentage) of the most frequently isolated Candida species according to the underlying condition.

ing around $60 \%$ of isolates, irrespective of the medical specialty. These results differ from recent American studies, which reported a lower isolation rate for C. albicans of around 50\% [10]. In our study, a single exception was noted in the oncology/haematology units where C. albicans represented less than $35 \%$ of isolates, while the majority of isolates were species such as C. glabrata, C. tropicalis and C. krusei which are less sensitive or resistant to azoles. This change in epidemiology of candidaemia in oncology/haematology confirms the results reported in a multicentre European study where C. albicans represented only $34.6 \%$ of isolates [9]. This emergence of non-albicans species is probably linked to FCZ prophylaxis, which is carried out mainly during periods of profound neutropenia, particularly after allogeneic bone marrow transplantation [24].

One notable finding from this investigation is the emergence of C. glabrata since 1996 (Figure 2). Analysis of the use of systemic antifungal drugs reveals an exponential increase in FCZ use between 1993 and 2002, with an increased use of low doses of this drug (generally used for prophylaxis) until 1996. The emergence of C. glabrata appears to be linked to the use of low-dose FCZ before 1997. Several reports have demonstrated that the use of sub-optimal doses of FCZ ( $<400 \mathrm{mg}$ ) can increase the frequency of $C$. glabrata as a cause of candidaemia in hospitalised patients $[25,26]$. It is also important to note that the prominent use of high-dose FCZ was accompanied by a progressive reduction in isolation of C. glabrata, which fell to $10 \%$ of isolates in 2003 . This reduction continued with the introduction of VCZ in 2002, leading to a significant reduction in use of high-dose FCZ (Figure 6). The low use of 5FC underlines the rarity of neuro-meningeal mycoses in our hospital. The introduction of lipid formulations of $\mathrm{AMB}$ has changed the use of this drug in patients likely to develop renal failure. In particular, AMBD is used widely as it has fewer side-effects and a broader range of indications than ABLC [27].

Although several mechanisms of resistance to azoles (FCZ, VCZ, ITZ) have been described in Candida, resulting 


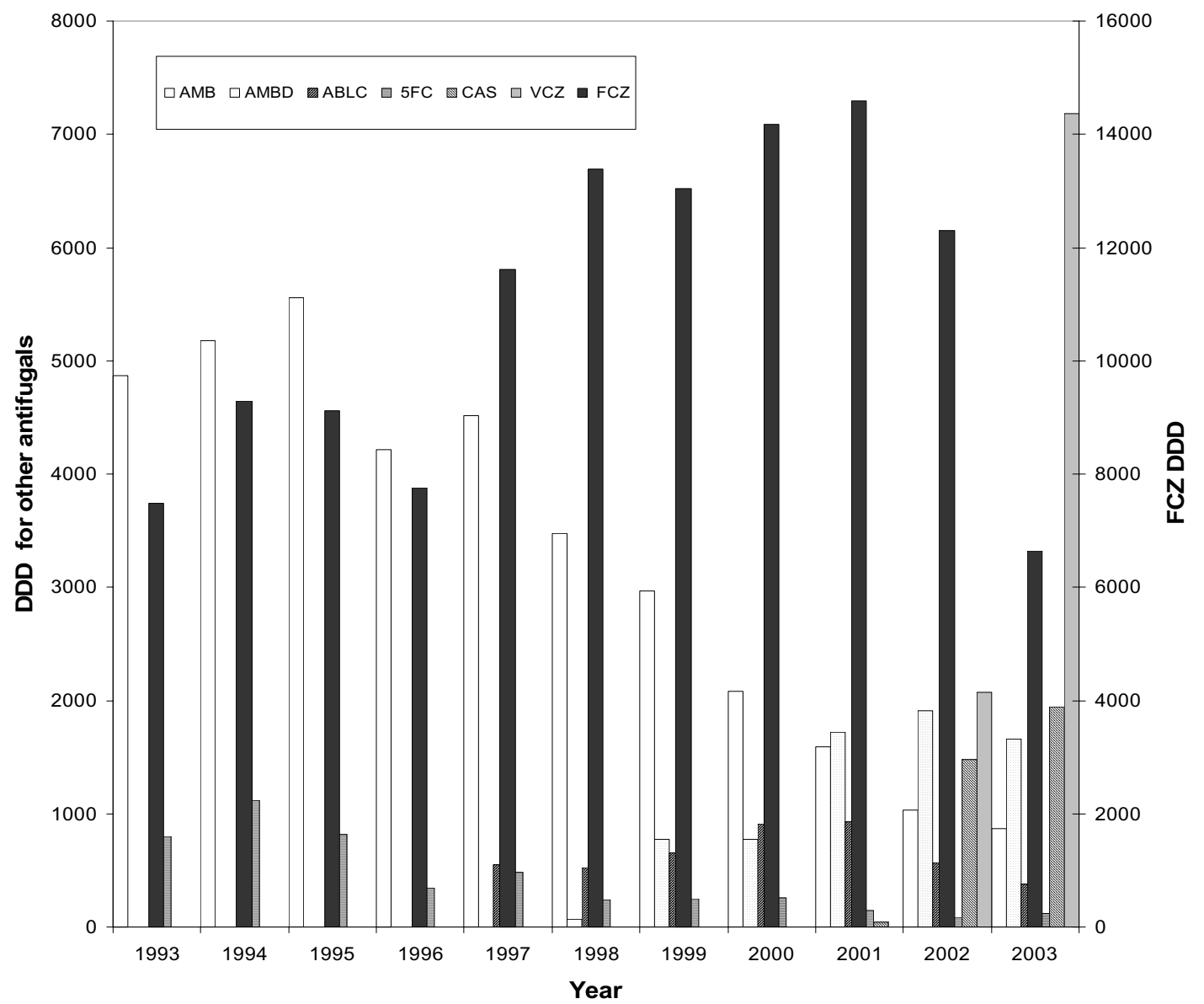

\section{Figure 4}

Annual consumption of systemic antifungal agents (daily doses) between 1993-2003. AMB: amphotericin B; AMBD; ambisome; ABLC: abelcet; 5FC: 5-fluorocytosine; CAS: caspofungin; VCZ: voriconazole; FCZ: fluconazole.

in overexpression of CDR1/CDR2 or MDR1 genes, or mutation in the ERG11 gene [28], the use of FCZ remains justified. In effect, the proportion of strains of Candida species that are resistant to FCZ remains low $(<10 \%)$. Among these, the percentage of $C$. glabrata strains varies from $0-23 \%$ according to the country $[15,29]$. Pressure for the selection of azole-resistant species has been reported by several authors [28], resulting in the introduction of recommendations for good use of antifungal drugs [18]. As far as FCZ is concerned, it has been recommended that patients are treated with curative doses of at least 400 $\mathrm{mg} /$ day, and that patients are stratified justifying antifungal therapy.

A reference system based on diagnostic strategies including clinical risk factors, scores for specific signs, radiological data and investigations based on culture of fungal pathogens has recently been set up. Taking into account the local ecology, the use of FCZ remains justified not just as prophylaxis but also as curative treatment for invasive candidosis.

The recommendations made distinguish two situations, prophylactic treatment in patients at high risk of invasive fungal infection, and treatment of clinically and mycologically documented invasive candidosis. The introduction of this reference system has resulted in a 13\% reduction in cost of systemic antifungal agents $(2.476 .438 €$ in 2004 versus 2.814.617 $€$ in 2003). Nevertheless, it does not appear to have had a significant impact on the incidence of candidaemia, which continues to rise (70 in 2004 vs. 38 in 1993). These data suggest that better diagnostic monitoring is required to allow earlier identification of patients at high risk of fungal infection. In addition to reference tests such as blood culture and histology this approach should include other biological markers 


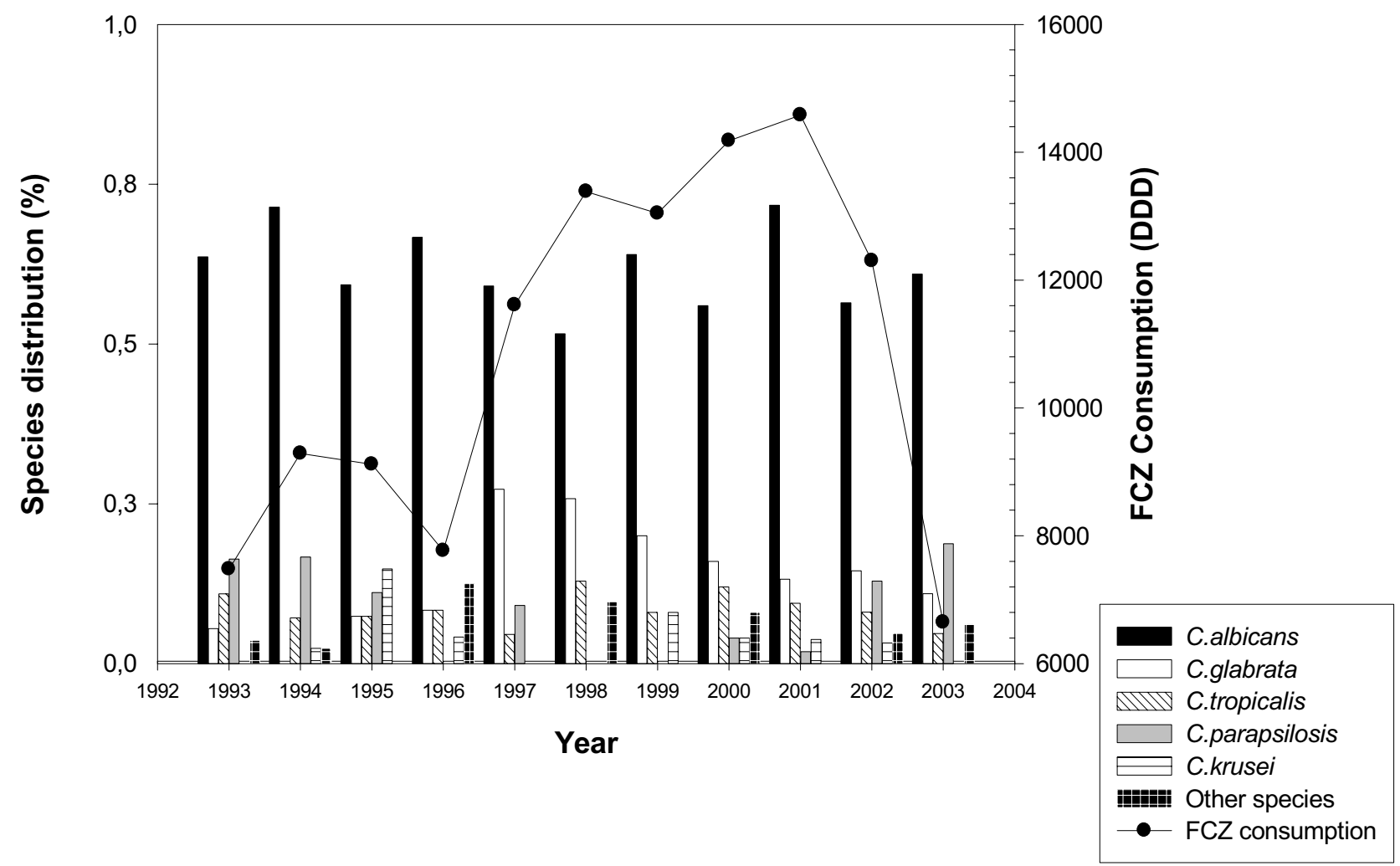

Figure 5

Evolution of isolation of Candida species in relation to fluconazole consumption between 1993-2003.

(inflammatory markers, determination of fungal colonisation, antigens, antibodies, nucleic acid, metabolites) whose circulation often precedes the isolation of fungi from a sterile site. Combination of these tests should improve the level of certainty of a fungal infection and the early initiation of antifungal treatment, resulting in a better prognosis. The efficacy of such measures should be evaluated regularly and adapted to the local ecology taking into account the increase in indications for the different drugs, the introduction of new antifungal agents and progress in diagnostic strategies.

\section{Conclusion}

The present study reveals that the number of cases of candidaemia in our hospital fell by more than 50\% in 1997 compared with 1993 and 2003. Analysis of antifungal use revealed that this period corresponded to a peak in prescription of oral forms of FCZ for prophylactic use. At this time the number of isolates of C. glabrata was almost $50 \%$ of the number of isolates of C. albicans. As C. glabrata is known to be resistant to FCZ, it is likely that this correlation is not due to chance.

\section{Competing interests}

The author(s) declare that they have no competing interests.

\section{Authors' contributions}

BS and DP conceived the study, directed its design and execution, and drafted the manuscript.

NF performed the mycological analysis, collected the data and participated to their interpretation. AC and AD collected and provided data on consumption of antifungal drugs, and participated to the redaction of the manuscript. AS participated in data collection and analysis and helped to draft the manuscript. DC managed the activity of the Parasitology-Mycology Clinical Laboratory and the laboratory staff. All authors read and approved the final manuscript.

\section{Acknowledgements}

We are grateful to all the hospital wards providing clinical data, and Dr. Valerie Hopwood for careful edition of the manuscript. We thank also Laurence Richard for her expert technical assistance. 


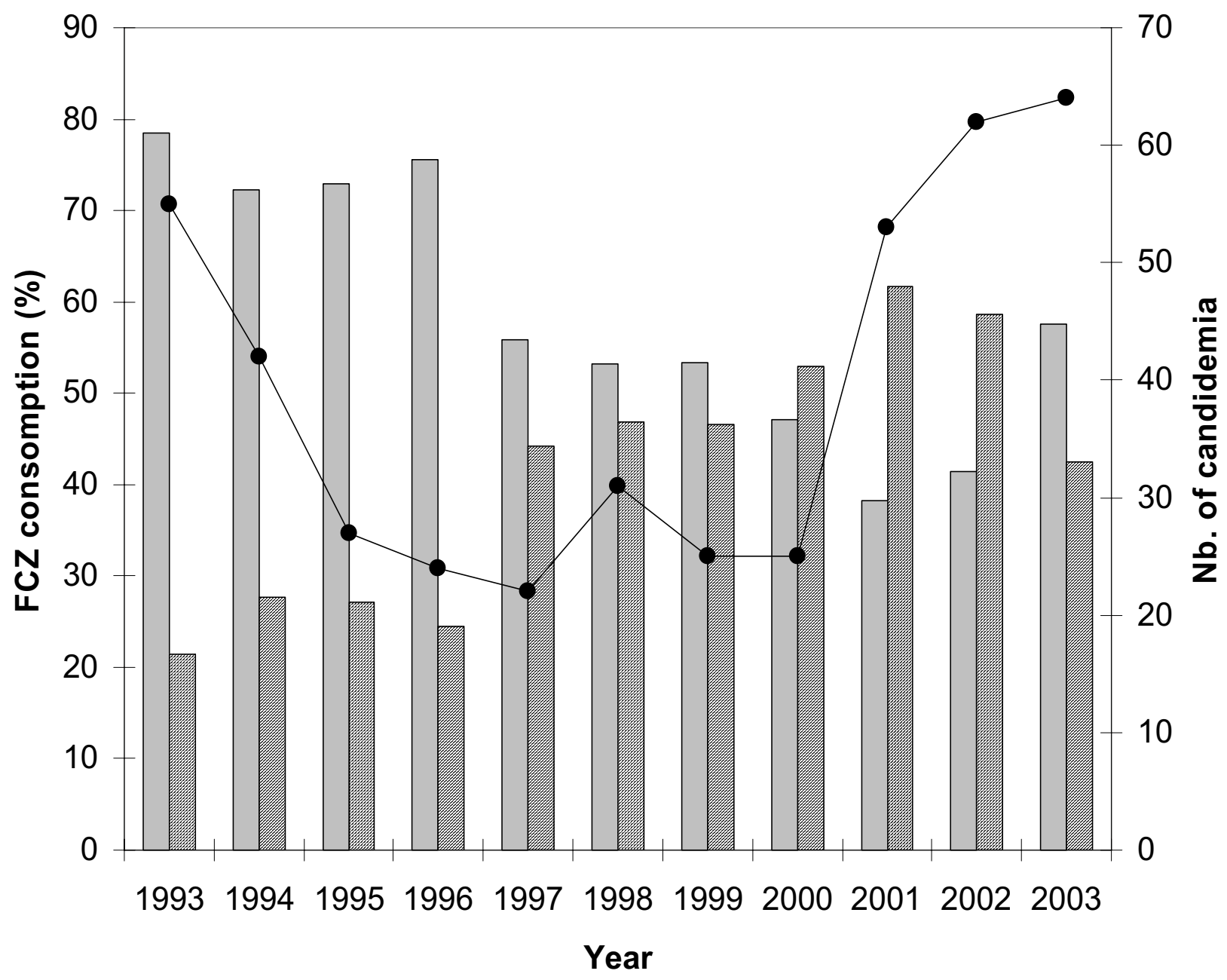

Low dose (50-100mg) $\square$ High dose (200-400mg) $\bullet-\mathrm{Nb}$. of candidemia

Figure 6

Annual consumption of low- and high-dose fluconazole in relation to the number of episodes of candidaemia between 19932003.

\section{References}

I. Hoyert DL, Kung HC, Smith BL: Deaths: preliminary data for 2003. Natl Vital Stat Rep 2005, 53:I-48.

2. Pittet D: Nosocomial bloodstream infections. In Prevention and control of nosocomial infections 3rd edition. Edited by: Wenzel RP. Baltimore: Williams and wilkins; 1997:7II-769.

3. Aubry-damon $\mathrm{H}$, Lemanissier $\mathrm{V}$, Lepoutre $\mathrm{A}$, Coignard $\mathrm{B}$, et al:: Prévalence des traitements antibiotiques à l'hôpital: résultats de l'enquête de prévalence nationale des infections nosocomiales 200I. Médecine \& Maladies Infectieuses 2004, 34:S130-S169.

4. Berrouane YF, Herwaldt LA, Pfaller MA: Trends in antifungal use and epidemiology of nosocomial yeast infections in a university hospital. J Clin Microbiol 1999, 37:531-537.

5. Pfaller MA, Diekema DJ, Jones RN, Sader HS, Fluit AC, Hollis RJ, Messer SA: International surveillance of bloodstream infections due to Candida species: frequency of occurrence and in vitro susceptibilities to fluconazole, ravuconazole, and voriconazole of isolates collected from 1997 through 1999 in the
SENTRY antimicrobial surveillance program. J Clin Microbiol 200I, 39:3254-3259.

6. Pfaller MA, Diekema DJ: Role of sentinel surveillance of candidemia: trends in species distribution and antifungal susceptibility. J Clin Microbiol 2002, 40:355 I-3557.

7. Wenzel RP: Nosocomial candidemia: risk factors and attributable mortality. Clin Infect Dis 1995, 20:153I-1534.

8. Eggimann P, Garbino J, Pittet D: Epidemiology of Candida species infections in critically ill non-immunosuppressed patients. Lancet Infect Dis 2003, 3:685-702.

9. Tortorano AM, Peman J, Bernhardt H, Klingspor L, Kibbler CC, Faure O, Biraghi E, Canton E, Zimmermann K, Seaton S, Grillot R: Epidemiology of candidaemia in Europe: results of 28-month European Confederation of Medical Mycology (ECMM) hospitalbased surveillance study. Eur J Clin Microbiol Infect Dis 2004, 23:317-322.

10. Hajjeh RA, Sofair AN, Harrison LH, Lyon GM, Arthington-Skaggs BA, Mirza SA, Phelan M, Morgan J, Lee-Yang W, Ciblak MA, Benjamin LE, Sanza LT, Huie S, Yeo SF, Brandt ME, Warnock DW: Incidence of 
bloodstream infections due to Candida species and in vitro susceptibilities of isolates collected from 1998 to 2000 in a population-based active surveillance program. J Clin Microbiol 2004, 42: 1519-1527.

II. Marr KA: Invasive Candida infections: the changing epidemiology. Oncology (Huntingt) 2004, 18:9-14.

12. Vincent JL, Anaissie E, Bruining H, Demajo W, el-Ebiary M, Haber J, Hiramatsu Y, Nitenberg G, Nystrom PO, Pittet D, Rogers T, Sandven $P$, Sganga G, Schaller MD, Solomkin J: Epidemiology, diagnosis and treatment of systemic Candida infection in surgical patients under intensive care. Intensive Care Med 1998, 24:206-216.

13. Wright WL, Wenzel RP: Nosocomial Candida. Epidemiology, transmission, and prevention. Infect Dis Clin North Am 1997, I I:4 I I-425.

14. Cha R, Sobel JD: Fluconazole for the treatment of candidiasis: 15 years experience. Expert Rev Anti Infect Ther 2004, 2:357-366.

15. Pfaller MA, Diekema DJ: Twelve years of fluconazole in clinical practice: global trends in species distribution and fluconazole susceptibility of bloodstream isolates of Candida. Clin Microbiol Infect 2004, I (Suppl I): I I-23.

16. Meyer MH, Letscher-Bru V, Jaulhac B, Waller J, Candolfi E: Comparison of Mycosis IC/F and plus Aerobic/F media for diagnosis of fungemia by the bactec $\mathbf{9 2 4 0}$ system. J Clin Microbiol 2004, 42:773-777.

17. Blot $\mathrm{S}$, Vandewoude $\mathrm{K}$ : Management of invasive candidiasis in critically ill patients. Drugs 2004, 64:2159-2I75.

18. Pappas PG, Rex JH, Sobel JD, Filler SG, Dismukes WE, Walsh TJ, Edwards JE: Guidelines for treatment of candidiasis. Clin Infect Dis 2004, 38: $161-189$.

19. Gudlaugsson O, Gillespie S, Lee K, Vande Berg J, Hu J, Messer S, Herwaldt L, Pfaller M, Diekema D: Attributable mortality of nosocomial candidemia, revisited. Clin Infect Dis 2003, 37: I I72-I I 77 .

20. Olaechea PM, Palomar M, Leon-Gil C, Alvarez-Lerma F, Jorda R, Nolla-Salas J, Leon-Regidor MA: Economic impact of Candida colonization and Candida infection in the critically ill patient. Eur J Clin Microbiol Infect Dis 2004, 23:323-330.

21. Rentz AM, Halpern MT, Bowden R: The impact of candidemia on length of hospital stay, outcome, and overall cost of illness. Clin Infect Dis 1998, 27:78|-788.

22. Richardson MD, Carlson P: Culture- and non-culture-based diagnostics for Candida species. In Candida and candidiasis Edited by: Calderone RA. Washington: ASM Press; 2002:387-394.

23. Edwards JE Jr, Bodey GP, Bowden RA, Buchner T, de Pauw BE, Filler SG, Ghannoum MA, Glauser M, Herbrecht R, Kauffman CA, Kohno S, Martino P, Meunier F, Mori T, Pfaller MA, Rex JH, Rogers TR, Rubin $\mathrm{RH}$, Solomkin J, Viscoli C, Walsh TJ, White M: International Conference for the Development of a Consensus on the Management and Prevention of Severe Candidal Infections. Clin Infect Dis 1997, 25:43-59.

24. Marr KA, Seidel K, White TC, Bowden RA: Candidemia in allogeneic blood and marrow transplant recipients: evolution of risk factors after the adoption of prophylactic fluconazole. J Infect Dis 2000, 181:309-316.

25. Snydman DR: Shifting patterns in the epidemiology of nosocomial Candida infections. Chest 2003, I 23:500S-503S.

26. Garbino J, Kolarova L, Rohner P, Lew D, Pichna P, Pittet D: Secular trends of candidemia over $I 2$ years in adult patients at a tertiary care hospital. Medicine (Baltimore) 2002, 8I:425-433.

27. Cagnoni PJ: Liposomal amphotericin B versus conventional amphotericin B in the empirical treatment of persistently febrile neutropenic patients. J Antimicrob Chemother 2002, 49(SuppI I):8I-86.

28. Sanglard D, Odds FC: Resistance of Candida species to antifungal agents: molecular mechanisms and clinical consequences. Lancet Infect Dis 2002, 2:73-85.

29. Baddley JW, Smith AM, Moser SA, Pappas PG: Trends in frequency and susceptibilities of Candida glabrata bloodstream isolates at a university hospital. Diagn Microbiol Infect Dis 200I, 39:199-20I.

\section{Pre-publication history}

The pre-publication history for this paper can be accessed here: http://www.biomedcentral.com/1471-2334/6/80/prepub

Publish with Biomed Central and every scientist can read your work free of charge

"BioMed Central will be the most significant development for disseminating the results of biomedical research in our lifetime. "

Sir Paul Nurse, Cancer Research UK

Your research papers will be:

- available free of charge to the entire biomedical community

- peer reviewed and published immediately upon acceptance

- cited in PubMed and archived on PubMed Central

- yours - you keep the copyright

Submit your manuscript here:

http://www.biomedcentral.com/info/publishing_adv.asp
BiolMedcentral 